\section{Athymic mice reveal a requirement for T-cell-microglia interactions in establishing a microenvironment supportive of $N f 1$ low-grade glioma growth}

\author{
Yuan Pan, ${ }^{1,6}$ Min Xiong, ${ }^{1,2,6}$ Ran Chen, ${ }^{1}$ Yu Ma, $^{1}$ \\ Courtney Corman, ${ }^{1}$ Meron Maricos, ${ }^{3}$ Urs Kindler, $^{3}$ \\ Marcus Semtner, ${ }^{3}$ Yi-Hsien Chen, ${ }^{1,4}$ \\ Sonika Dahiya, ${ }^{5}$ and David H. Gutmann ${ }^{1}$
}

${ }^{1}$ Department of Neurology, Washington University School of Medicine, St. Louis, Missouri 63110, USA; ${ }^{2}$ Reproductive Medicine Center, Tongji Hospital, Tongji Medical College, Huazhong University of Science and Technology, Wuhan 430030, China; ${ }^{3}$ Cellular Neuroscience, Max-Delbrück-Center for Molecular Medicine in the Helmholtz Association (MDC), Berlin 13125, Germany; ${ }^{4}$ Genome Engineering and iPSC Center (GEIC), Washington University School of Medicine, St. Louis, Missouri 63110, USA; ${ }^{5}$ Division of Neuropathology, Washington University School of Medicine, St. Louis, Missouri 63110, USA

Pediatric low-grade gliomas (LGGs) frequently do not engraft in immunocompromised mice, limiting their use as an experimental platform. In contrast, murine Neurofibromatosis-1 (Nf1) optic LGG stem cells (o-GSCs) form glioma-like lesions in wild-type, but not athymic, mice following transplantation. Here, we show that the inability of athymic mice to support o-GSC engraftment results from impaired microglia/macrophage function, including reduced expression of Ccr2 and Ccl5, both of which are required for o-GSC engraftment and Nf1 optic glioma growth. Impaired Ccr 2 and Ccl5 expression in athymic microglia/macrophages was restored by T-cell exposure, establishing T-cell-microglia/macrophage interactions as critical stromal determinants that support NF1 LGG growth.

Supplemental material is available for this article.

Received December 12, 2017; revised version accepted March 13, 2018.

Immunocompromised mice (e.g., athymic Foxn $1^{-/-}$mice) are common tools for human tumor xenograft studies, including high-grade gliomas (Morton and Houghton 2007; Venkatesh et al. 2017). While malignant glioma stem cells readily form tumors in athymic mice, no successful ectopic xenografts have been reported for low-grade glioma (LGG) cells (Raabe et al. 2011). One of the critical determinants of LGG formation and growth is a permissive microenvironment composed of nonneoplastic cells, including immune system cells. This dependency on immune

\footnotetext{
[Keywords: tumor microenvironment; stroma; monocyte; chemokines] ${ }^{6}$ These authors contributed equally to this work. Corresponding author: gutmannd@wustl.edu

Article published online ahead of print. Article and publication date are online at http://www.genesdev.org/cgi/doi/10.1101/gad.310797.117.
}

system-like cells is highlighted by the high percentage $(35 \%-50 \%)$ of $\mathrm{Ibal}^{+}$microglia/macrophages (Simmons et al. 2011) as well as increased numbers of T cells in these tumors (Yang et al. 2011; Griesinger et al. 2013).

Since relative immunodeficiency is required to accept human cells for rodent xenografting studies and since no validated human LGG lines are currently available, genetically engineered mouse (GEM) models of pediatric LGGs have served as experimental platforms to define the role of immune system-like cells in LGG pathogenesis. To this end, Neurofibromatosis-1 (Nf1) GEM strains have been used to define the conditions critical for optic gliomas (grade I pilocytic astrocytomas [PAs]) arising in the NF1 brain tumor predisposition syndrome (Bajenaru et al. 2003; Zhu et al. 2005). Unlike grade II LGGs, which can progress to high-grade gliomas, NF1-associated pediatric LGGs do not transform into malignant gliomas (Hoyt and Baghdassarian 1969) and rarely result in reduced life expectancy.

Consistent with a critical role for immune system cells (monocytes) in Nf1 optic glioma formation and maintenance, genetic $C x 3 c r 1$ reduction delays tumor formation (Pong et al. 2013), and genetic elimination of CD11b microglia/macrophages (Simmons et al. 2011) or pharmacological microglial inhibition (Daginakatte and Gutmann 2007; Daginakatte et al. 2008) reduces optic glioma proliferation. Moreover, murine Nf1 optic gliomaassociated microglia express the Ccl5 chemokine such that neutralizing Ccl5 antibodies attenuates optic glioma growth in vivo (Solga et al. 2015).

Within these murine $N f 1$ optic gliomas are cancer stem cells, termed optic glioma stem cells (o-GSCs), which are capable of self-renewal, multilineage differentiation, and the generation of glioma-like lesions following transplantation into the brain stems of naïve immunocompetent wild-type mice (Chen et al. 2015). Interestingly, o-GSCs do not form tumors in immunocompromised athymic $\left(\right.$ Foxn $\left.1^{-/-}\right)$mice, suggesting that these T-cell-defective mice lack a microenvironment supportive of o-GSC engraftment. To define the etiologies for the failure of o-GSCs to engraft in athymic mice, we demonstrate for the first time that athymic mice have impaired brain microglia/macrophage function (phagocytosis and lipopolysaccharide [LPS]-mediated cytokine production) as well as reduced expression of Ccr2 and Cc15 relative to their wild-type counterparts. Consistent with a key role for Ccr2 and Ccl5 in gliomagenesis and optic glioma maintenance, o-GSCs do not form glioma-like lesions in either Ccr2- or Ccl5-deficient mice, and treatment with Ccl2-neutralizing antibodies attenuates Nf1 optic glioma growth in vivo. In addition, exposure of athymic mouse brain microglia to activated, but not naïve, wild-type $\mathrm{T}$ cells or T-cell-conditioned medium is sufficient to restore normal microglial Ccr2 and Ccl5 expression. Taken together, these observations establish an obligate role for T cells in monocyte-mediated stromal support of $N f 1$ LGG pathogenesis.

(C) 2018 Pan et al. This article is distributed exclusively by Cold Spring Harbor Laboratory Press for the first six months after the full-issue publication date (see http://genesdev.cshlp.org/site/misc/terms.xhtml). After six months, it is available under a Creative Commons License (Attribution-NonCommercial 4.0 International), as described at http://creativecommons.org/licenses/by-nc/4.0/. 


\section{Results and Discussion}

\section{Athymic mice reveal defects in microglia/macrophages}

Because athymic mice lack Foxn1 expression, we first sought to determine whether Foxn1 loss might alter the composition of brain stromal cells previously implicated in glioma maintenance. We focused on the brain stem, as this is the second most common region for glioma formation in children with NF1 (Mahdi et al. 2017) and represents a location suitable for tumor cell engraftment studies (Chen et al. 2015). In contrast to findings in athymic BALB/c mice (Htain et al. 1994), we observed no differences in astrocyte $\left(\mathrm{GFAP}^{+}\right.$cell) (Supplemental Fig. S1A), endothelial cell $\left(\mathrm{CD} 34^{+}\right.$cell) (Supplemental Fig. S1B), oligodendrocyte precursor (Olig2 ${ }^{+}$cell) (Supplemental Fig. S1C), or myeloid cell (resident microglia and peripheral monocyte/macrophage; $\mathrm{Ibal}^{+}$cell) (Fig. 1A) content in C57BL/6 athymic mouse brain stems relative to strain-matched wild-type counterparts.

Interestingly, athymic mice harbored an increased percentage of amoeboid-shaped $\mathrm{Ibal}^{+}$cells (Fig. 1A), suggestive of an altered functional state. However, Foxn1 is expressed primarily in the thymus and skin (Nehls et al. 1994) and not in the mouse or human brain or MACS-isolated microglia/macrophages (Supplemental Fig. S1D-G). Foxn1 mutation can increase Foxp $3^{+}$regulatory T-cell content (Albuquerque et al. 2012; Oh et al. 2017), but no Foxp $3^{+}$cells were detected in either wild-type or athymic mouse brain stems (Supplemental Fig. S1H). The absence of $\mathrm{T}$ cells in the naïve mouse brain prompted a further exploration of Foxn $1^{-/-}$microglia/macrophage properties.

Using $C \times 3 c r 1^{+/ G F P}$ and $C c r 2^{+/ R F P}$ reporter mice, we and others have demonstrated that brain monocytes (Iba1 ${ }^{+}$cells) can be either resident brain microglia $\left(\mathrm{Cx} 3 \mathrm{cr}^{+} \mathrm{Ccr}^{-}\right)$or peripheral macrophages $\left(\mathrm{Ccr}^{+}\right)$(Fig. 1B). In this regard, $\sim 95 \%$ of the brain monocytes are resident brain microglia $\left(\mathrm{Cx} 3 \mathrm{cr}^{+} \mathrm{Ccr}^{-}\right)$, while the rest are likely peripheral macrophages $\left(\mathrm{Ccr}^{+}\right)($Mizutani et al. 2012).

A

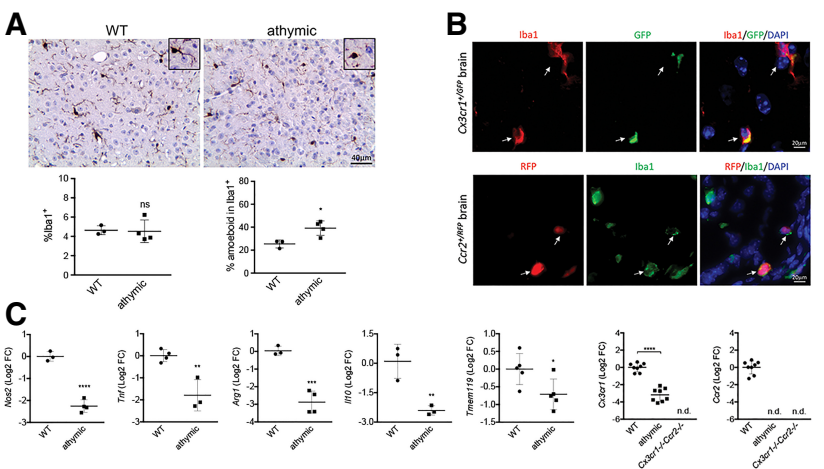

Figure 1. Athymic mice reveal morphological defects in microglia. (A) Immunohistochemistry (IHC) reveals no differences in $\mathrm{Iba}^{+}{ }^{+}$cell content; however, more amoeboid Ibal ${ }^{+}$cells were found in athymic mice. $\left.{ }^{*}\right) P=0.0123$; (ns) not significant $(P \geq 0.05)$. Bars, $40 \mu \mathrm{m} .(B)$ Immunostaining of $\mathrm{Cx} 3 \mathrm{crl}^{+/ \mathrm{GFP}}$ and $\mathrm{Ccr} 2^{+/ \mathrm{RFP}}$ mouse brain stems reveals colocalization of Ibal and GFP/RFP. Bars, $20 \mu \mathrm{m}$. (C) Reduced Nos2 ([****] $P<0.0001), \operatorname{Tnf}\left(\left[{ }^{* *}\right] P=0.0051\right), \operatorname{Arg} 1([* * *] P=0.0007)$, Il10 ([**] $P=0.0084)$, Tmem119 ([*] $P=0.0325)$, Cx3cr1 ([****] $P<$ 0.0001 ), and Ccr2 expression was observed in athymic mouse brain stems. $\mathrm{Cx} 3 \mathrm{cr}^{-/-} \mathrm{Ccr}^{-/-}$brain stems were used as a negative control. (n.d.) Not detected.

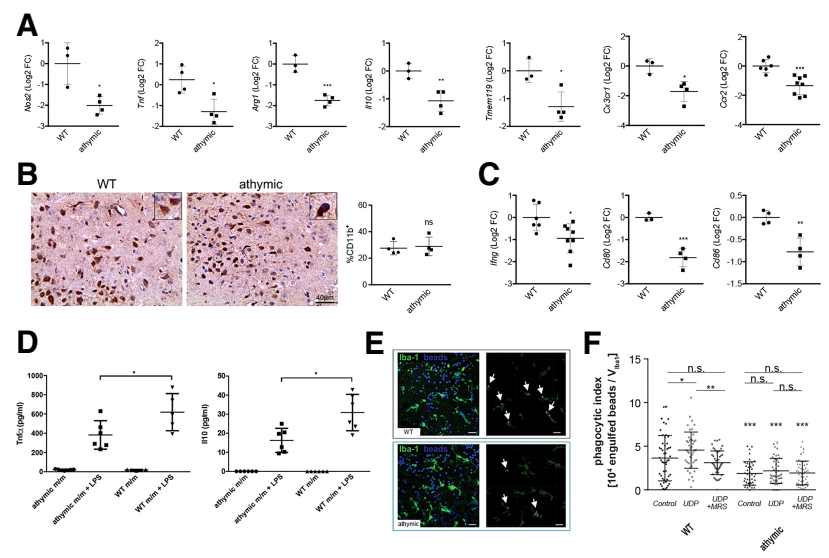

Figure 2. Reduced microglia/macrophage gene expression in athymic mice. $(A)$ Reduced Nos2 ([*] $P=0.0138), \operatorname{Tnf}\left(\left[{ }^{*}\right] P=0.013\right), \operatorname{Arg} 1$ ([***] $P=0.0008)$, Il10 ([**] $P=0.0095)$, Tmem119 ([*] $P=0.0185)$, Cx3cr1 $([*] P=0.0147)$, and $C c r 2\left(\left[{ }^{* * *}\right] P=0.0008\right.$ ) expression was detected in athymic mouse brain $\mathrm{CD} 1 \mathrm{~b}^{+}$cells. $(B)$ No difference in the percentages of $\mathrm{CD} 1 \mathrm{~b}^{+}$cells in athymic versus wild-type mouse brain stems was observed. Bar, $40 \mu \mathrm{m}$. (C) Reduced Ifng $\left(\left[^{*}\right] P=\right.$ $0.0176), C d 80\left(\left[{ }^{* * *}\right] P=0.001\right)$, and $C d 86\left(\left[{ }^{* *}\right] P=0.0041\right)$ expression was detected in $\mathrm{CD} 11 \mathrm{~b}^{+}$cells isolated from athymic mouse brains. (FC) Fold change. $(D)$ Reduced Tnfa $\left(\left[{ }^{*}\right] P=0.0464\right)$ and Illo $\left(\left[{ }^{*}\right] P=\right.$ $0.0107)$ was detected following LPS stimulation in athymic mouse brain microglia/macrophages. (E) Representative confocal images (left) of Ibal ${ }^{+}$cells (green) and latex beads (blue) in mouse brain slices, with three-dimensional reconstructions (right) shown in gray and indicated by white arrows. Bars, $20 \mu \mathrm{m}$. (F) A lower phagocytic index was found in athymic mouse microglia/macrophages. No increase in phagocytic activity was observed in athymic mice following UDP stimulation. $\left(^{* * *}\right) P<0.001, t$-test comparison with their wildtype counterparts. (MRS) MRS2578, a UDP-P2yr6 inhibitor; (ns) not significant $(P \geq 0.05)$.

To define the impact of Foxn1 mutation on microglia, we first examined the expression of transcripts previously implicated in microglia/macrophage function, including inflammatory mediators (Nos2, Tnf, Arg1, and I110), chemokine receptors (Cx3cr1 and Ccr2), and genes involved in microglia/macrophage homeostasis (Cap1, Erg1, P2ry12, and Tmem119). While no differences in Cap1, Erg1, or P2ry12 expression were detected (data not shown), Nos2, Tnf, Arg1, I110, Tmem119, Cx3cr1, and Ccr2 expression was reduced in the brain stems of athymic, relative to wild-type, mice (Fig. 1C). This reduction was also observed in acutely isolated $\mathrm{CD}_{11 \mathrm{~b}^{+} \text {cells }}$ using magnetic-activated cell sorting (MACS) (Fig. 2A), where the percentages of $\mathrm{CD}_{11} \mathrm{~b}^{+}$cells were similar in wild-type and athymic brain stems (Fig. 2B). Additionally, the expression of several antigen presentation-related genes (Ifng, Cd80, and Cd86) was reduced in isolated athymic mouse brain microglia/macrophages relative to their wild-type counterparts (Fig. 2C).

Second, based on reduced baseline Tnf and $I 110$ expression in athymic mouse microglia, we next sought to determine whether Foxn $1^{-/-}$microglia have impaired Tnfa and Il10 protein production following LPS stimulation. Consistent with a defect in microglia function, reduced Tnfa and Illo levels were detected in the culture medium (CM) of athymic mouse microglia relative to their wildtype counterparts (Fig. 2D).

Third, we determined the in situ phagocytic activity of Foxn1 $1^{-/-}$microglia. Under both basal conditions and following UDP stimulation, athymic mouse microglia 
exhibited reduced phagocytosis compared with their wildtype counterparts (Fig. 2E,F). Whereas UDP increased phagocytosis in wild-type microglia/macrophages, which was blocked by the MRS inhibitor, the phagocytic index was lower in Foxn1 $1^{-/-}$microglia under all conditions.

Collectively, these findings establish that Foxn1-/brain microglia/macrophages are abnormal with respect to morphology, gene expression, and functional properties, raising the intriguing possibility that athymic mouse brain microglia are defective in their ability to provide a supportive microenvironment for o-GSC engraftment.

\section{Reduced expression of Ccr2 in athymic mouse microglia/ macrophages inhibits tumor formation}

The reduction in $C x 3 c r 1$ and $C c r 2$ levels in athymic mouse microglia/macrophages is interesting, since CX3CR1 and CCR2 are critical regulators of microglia/ macrophage function relevant to malignant glioma growth (Feng et al. 2015; Chen et al. 2017). As such, Cx3Cr1 and Ccr2 are enriched in naïve mouse brain microglia/macrophages (Supplemental Fig. S2A), consistent with previous findings that $\mathrm{Cx} 3 \mathrm{cr} 1$ and $\mathrm{Ccr} 2$ are expressed primarily by brain microglia and peripheral macrophages, respectively (Mizutani et al. 2012). Since we demonstrated previously that reduced $C \times 3$ cr 1 expression delayed, but did not abrogate, murine Nf1 optic gliomagenesis (Pong et al. 2013), we specifically focused on the role of Ccr2 in o-GSC engraftment.

First, we sought to determine whether Ccr2 deficiency results in altered brain stem microglia morphology and gene expression. Similar to athymic mice, $C \mathrm{cr} 2^{-/-}$mice had more amoeboid Iba1 ${ }^{+}$cells (Fig. 3A), with no change in total $\mathrm{Iba}^{+}$cells (Supplemental Fig. S2B). In addition, Nos2, Arg1, I110, and Tmem119 expression was decreased in the $\mathrm{Ccr}^{-/-}$mouse brain stems relative to their wildtype counterparts (Supplemental Fig. S2C). Second, to as-

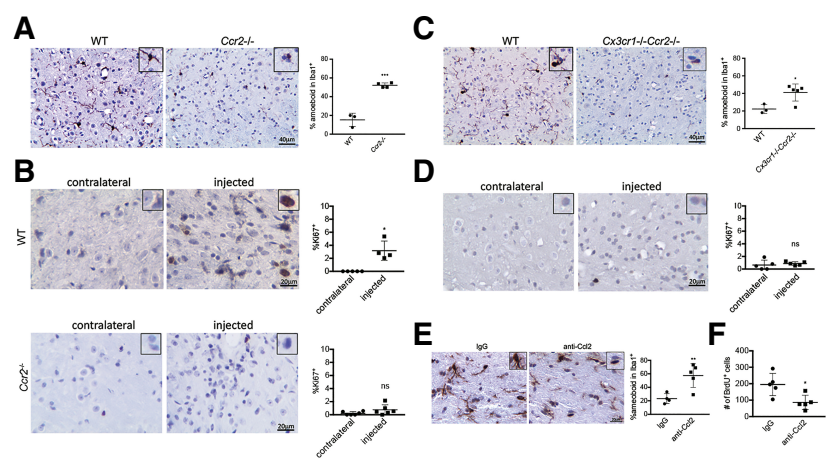

Figure 3. Ccr2 is required for murine $N f 1$ optic gliomagenesis. (A) IHC reveals more amoeboid Iba1 ${ }^{+}$cells in $\mathrm{Ccr}^{-P^{-}}$brain stems. $(* * *) P=0.0002$. $(B$, top panel) IHC of wild-type brain stems implanted with o-GSCs reveals more $\mathrm{Ki} 67^{+}$cells in the injected, relative to the contralateral, sites. $\left(^{*}\right) P=0.0019$. (Bottom panel) IHC of $C \mathrm{cr} 2^{-1-}$ brain stems implanted with o-GSCs shows no differences in $\mathrm{Ki} 67^{+}$cells between contralateral and injected sites. $(C)$ IHC reveals more amoeboid Ibal ${ }^{+}$cells in $\mathrm{Cx} 3 \mathrm{cr} 1^{-/-} \mathrm{Ccr} 2^{-/-}$brain stems. $\left(^{*} P=0.0222\right.$. (D) IHC of $\mathrm{Cx} 3 \mathrm{cr}^{-/-} \mathrm{Ccr} 2^{-/-}$brain stems implanted with o-GSCs shows similar Ki $67^{+}$cell content between contralateral and injected sites. $(E)$ IHC reveals more amoeboid Iba $1^{+}$cells in the optic nerve/chiasm of $N f 1^{\text {flox/mut }}$; GFAP-Cre mice treated with anti-Ccl2-neutralizing antibodies relative to control IgG. $(* *) P=0.0086$. $(F)$ Reduced numbers of $\mathrm{BrdU}^{+}$cells were observed in anti-Ccl2-treated, relative to IgG-treated, mice. $\left({ }^{*}\right) P=0.0164$. (FC) Fold change; (ns) not significant $(P \geq 0.05)$. certain whether Ccr2 is required for murine LGG formation, o-GSCs were implanted into the brain stems of wild-type and $\mathrm{Ccr}^{-/-}$mice. While o-GSCs formed glioma-like lesions in wild-type mice 6 mo after transplantation, as evidenced by an increased percentage of $\mathrm{Ki} 67^{+}$ cells at injection sites, no tumors formed in $\mathrm{Ccr}^{-1-}$ mice (Fig. 3B). The o-GSC cells were labeled with mCherry, and mCherry ${ }^{+}$cells were detected by immunohistochemistry (IHC) at sites where tumors formed (Supplemental Fig. S2D). Similarly, $C \times 3 c r 1^{-1-} C c r 2^{-/-}$mice exhibited more amoeboid $\mathrm{Ibal}^{+}$cells (Fig. 3C) and did not support glioma formation following o-GSC transplantation (Fig. 3D). Third, to define the requirement for Ccr2 activation in $N f 1$ optic glioma maintenance, $N f 1^{\text {flox/mut }}$; GFAP-Cre mice (Bajenaru et al. 2003) were treated at 3 mo of age with Ccl2-neutralizing antibodies to block Ccr2 engagement. Following anti-Ccl2 treatment, the percentage of amoeboid Iba $1^{+}$cells was increased relative to the IgG-treated control group (Fig. 3E), similar to Ccr2 ${ }^{-/-}$ brain stems (Fig. 3A), without any changes in total Iba $1^{+}$ cells (Supplemental Fig. S2E). Importantly, mice receiving anti-Ccl2 antibody therapy had attenuated tumor proliferation (reduced BrdU ${ }^{+}$cells) (Fig. 3F). Taken together, these data establish that the $\mathrm{Ccl} 2 / \mathrm{Ccr} 2$ axis is required for murine $N f 1$ optic gliomagenesis.

\section{Ccl5 is necessary and sufficient for glioma formation}

Tumor-associated monocytes (TAMs) can produce paracrine factors that increase glioma growth (Solga et al. 2015; Chang et al. 2016). As such, we previously used RNA sequencing of TAMs isolated from this particular murine $N f 1$ optic glioma model to demonstrate that microglial Ccl5 drives murine $N f 1$ optic glioma growth in vivo (Solga et al. 2015). In light of the defects observed in Foxn $1^{-/-}$microglia, we therefore examined Ccl5 production: At both the RNA and protein levels, $C c 15$ was reduced in the brain stems of athymic mice (Fig. 4A,B). Since Cc15 is expressed primarily by microglia/macrophages in nonneoplastic brains (Supplemental Fig. S3A), Cc15 expression was also reduced in Foxn1 ${ }^{-1-}$ MACS-isolated brain microglia (Fig. 4C).

In order to better characterize the spectrum of potential growth factors reduced in Foxn1 $1^{-1-}$ microglia, RNA sequencing of the brain stems of wild-type and athymic mice was performed. Interestingly, only three growth factors (I116, Cxcl10, and Ccl8) normally expressed in microglia/macrophages (Supplemental Fig. S3B-D) were reduced in athymic, relative to wild-type, mouse brain stems (Supplemental Fig. S3E). These differentially expressed genes were validated by quantitative real-time PCR (qRT-PCR) using independently derived brain stem tissues and MACS-isolated microglia (Supplemental Fig. S3E). However, no similarities in the patterns of differentially expressed genes between wild-type and athymic mouse brain stems were observed relative to those reported for microglia in the setting of inflammatory or neurodegenerative diseases (Keren-Shaul et al. 2017; Krasemann et al. 2017; data not shown).

Since Ccl5 inhibition inhibits Nf1 optic glioma growth in vivo (Solga et al. 2015), we sought to determine whether Ccl5 regulates the expression of I116, Cxcl10, or Ccl8. Consistent with $\mathrm{Ccl} 5$ as a tumor microenvironment master regulator, all three genes were decreased in $\mathrm{Ccl5}^{-/}$, relative to wild-type, mouse brain stems and MACS-isolated microglia/macrophages (Supplemental Fig. S3F,G). 


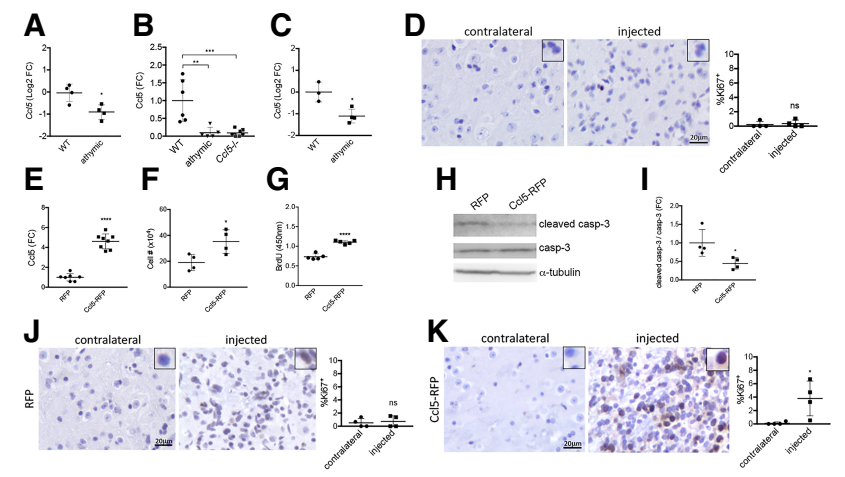

Figure 4. Ccl5 is necessary and sufficient for murine LGG tumor formation. (A) Reduced $C c 15$ expression was observed in athymic brain

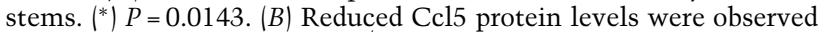
in athymic brain stems. $C c 15^{-1-}$ brain stems were used as a negative control. (**) $P=0.0093$; (**) $P=0.001$. $(C)$ Reduced $C c 15$ expression was observed in CD1 $1 \mathrm{~b}^{+}$cells isolated from athymic mouse brains. (*) $P=0.0123$. (D) IHC of $C c 15^{-/-}$brain stems implanted with o-GSCs shows no differences in $\mathrm{Ki}_{6} 7^{+}$cell content between the contralateral and injected sites. (E) Increased CM Ccl5 levels were observed in Ccl5-RFP-expressing, relative to RFP-expressing, o-GSCs. $(* * * *) P<0.0001$. ( F ) Increased cell numbers were observed in Ccl5RFP-expressing, relative to RFP-expressing, o-GSCs. $\left(^{*}\right) P=0.0266$. $(G)$ Increased BrdU incorporation was detected in Ccl5-RFP-expressing, relative to RFP-expressing, o-GSCs. $\left.{ }^{* * * *}\right) P<0.0001$. $(H, I) \mathrm{Re}-$ duced cleaved caspase-3 (casp-3) levels were detected in Ccl5-RFPexpressing, relative to RFP-expressing, o-GSCs following normalization to total casp-3. $\left(^{*}\right) P=0.0296$. $(J, K)$ IHC of athymic mouse brain stems implanted with o-GSCs expressing RFP $(J)$ or Ccl5-RFP $(K)$. No differences in $\mathrm{Ki} 67^{+}$cell content were observed in the RFP-implanted mice between contralateral and injected sites. An increased percentage of $\mathrm{Ki} 67^{+}$cells was observed in Ccl5-RFP-injected, relative to contralateral, sites. $\left(^{*}\right) P=0.0292$. (FC) Fold change; (ns) not significant $(P \geq 0.05)$.

To determine whether Ccl5 is necessary for tumor formation, o-GSCs were implanted into the brain stems of $\mathrm{Ccl5}^{-1-}$ mice, but no glioma-like lesions were detected (Fig. 4D). Next, to establish sufficiency, we ectopically expressed Ccl5-RFP or RFP (control) in o-GSCs (Fig. 4E). Ectopic Ccl5-RFP expression increased o-GSC numbers and BrdU incorporation but decreased cleaved caspase-3 expression in vitro (Fig. 4F-I). When RFP-Ccl5- or RFPexpressing o-GSCs were implanted into the brain stems of athymic mice, only RFP-Ccl5-expressing o-GSCs generated proliferating glioma-like lesions (Fig. 4J,K). Taken together, these findings strongly implicate Ccl5 as a key stromal determinant in o-GSC gliomagenesis.

\section{T cells stimulate microglia Cc15 production}

Athymic mice harbor mutations in the Foxn1 gene, which, as a transcription factor, could potentially regulate Cc15 expression in microglia/macrophages. However, Foxn1 RNA is not expressed in the mouse or human brain or in MACS-isolated microglia/macrophages (Supplemental Fig. S1D-G). The absence of Foxn1 expression in the brain raises the intriguing possibility that T cells regulate $C c 15$ expression in microglia/macrophages.

Previous studies have demonstrated that interactions between $T$ cells and microglia/macrophages result in the production of chemokines/cytokines that can shape the tumor microenvironment (Chabot et al. 1999). Using
CD3 as a pan-T-cell marker, increased $\mathrm{CD}^{+}$cells were detected in murine $N f 1$ optic gliomas $\left(N f 1^{\text {flox/mut }}\right.$; GFAP-Cre mice) (Fig. 5A) as well as within the glioma-like lesions following o-GSC engraftment in wild-type mice. In contrast, $\mathrm{CD}^{+}$cells were not found in normal brains (Fig. 5B) or o-GSC-injected sites where no tumors formed (Supplemental Fig. S4A). Finally, consistent with reports describing increased numbers of $\mathrm{T}$ cells in sporadic human PAs (Yang et al. 2011; Griesinger et al. 2013), CD3 ${ }^{+}$ cells were also observed in human NF1-PA ( $n=3$ tumors), with no or only rare $\mathrm{CD}^{+}$cells in normal brains (Fig. $5 \mathrm{C}$; Supplemental Fig. S4B).

To determine whether $\mathrm{T}$ cells can stimulate athymic mouse brain microglia to express $C c 15$, we isolated T cells from the spleens of wild-type mice and cocultured them with Foxn1 $1^{-/-}$microglia. After 24 h, CM was collected for Ccl5 enzyme-linked immunosorbent assay (ELISA),

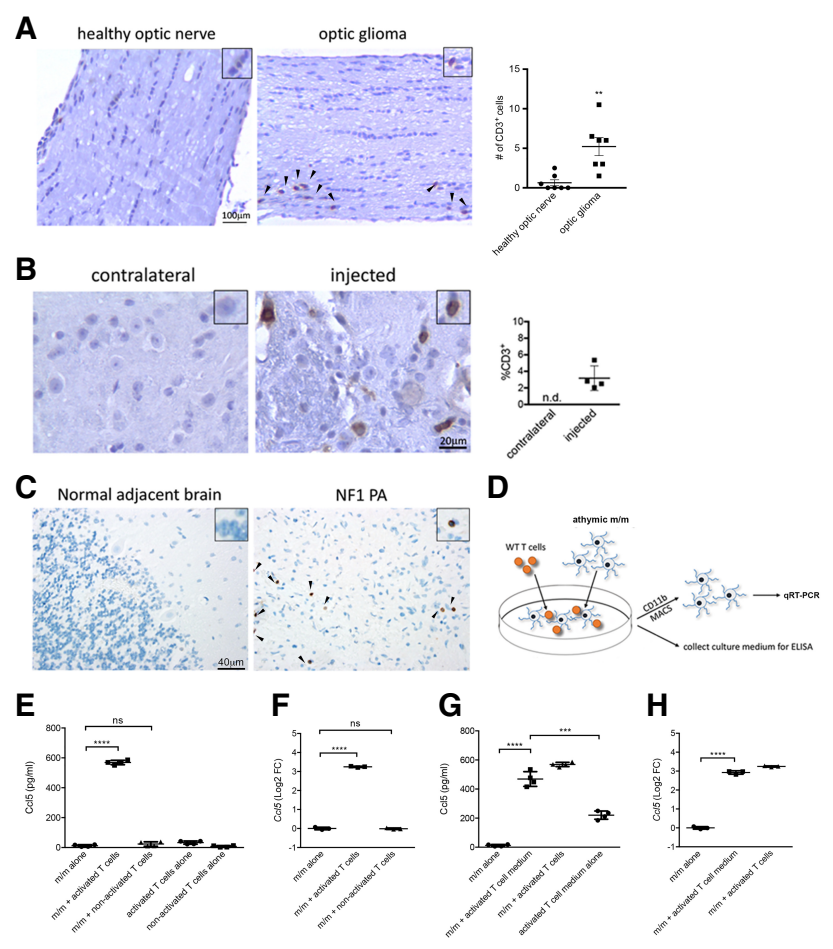

Figure 5. T cells induce athymic mouse microglia/macrophage Ccl5 expression. (A) IHC reveals increased $\mathrm{CD}^{+}$cells (arrowheads) in the optic nerves/chiasm of $N f 1^{\text {flox/mut }}$; GFAP-Cre (optic glioma), relative to $N f 1^{\text {flox } / \text { flox }}$, mice (healthy optic nerves). $\left.{ }^{* *}\right) P=0.0025$. Bar, $100 \mu \mathrm{m}$. (B) IHC reveals $\mathrm{CD}^{+}$cells at injected glioma-like lesion-bearing sites, but not in the contralateral sites, of wild-type mice. (n.d.) Not detectable. Bar, $20 \mu \mathrm{m}$. (C) IHC reveals $\mathrm{CD}^{+}$cells in human NF1- PA but not in the normal adjacent brain. Bar, $40 \mu \mathrm{m}$. $(D)$ Wild-type T cells were cocultured with athymic mouse brain microglia/macrophages $(\mathrm{m} / \mathrm{m})$ followed by CM collection for enzyme-linked immunosorbent assay (ELISA) and CD11 b cell capture (MACS) for qRT-PCR. (E) ELISA reveals increased Ccl5 production following exposure of athymic mouse microglia/macrophages to activated, but not naïve, wildtype T cells relative to microglia/macrophages alone. $\left.{ }^{* * * *}\right) P<0.0001$. (F) Increased Cc15 RNA expression was observed in $\mathrm{CD}_{11 \mathrm{~b}^{+} \text {micro- }}$ glia/macrophages exposed to activated, but not nonactivated, wildtype T cells. $\left({ }^{* * * *}\right) P<0.0001 .(G, H)$ Increased $C c 15$ protein $(G)$ and RNA $(H)$ expression in athymic mouse brain microglia/macrophages following exposure to activated wild-type T-cell CM as well as activated wild-type $\mathrm{T}$ cells relative to microglia/macrophages alone. $\left.{ }^{(* * *)} P<0.0001 ;{ }^{* * *}\right) P=0.001$. (FC) Fold change; $(\mathrm{ns})$ not significant. 
and microglia/macrophages were captured by MACS for Cc15 RNA quantitation using qRT-PCR (Fig. 5D). Since productive T-cell-microglia/macrophage interactions often require T-cell activation (Chabot et al. 1999, 2002), $\mathrm{T}$ cells were activated with anti-CD $\varepsilon$ and anti-CD28 antibodies in vitro. Following activation, increased Ccl5 levels were detected in the CM (Fig. 5E) as well as in MACS-isolated athymic mouse brain microglia from these cocultures (Fig. 5F). Consistent with a model in which T-cell activation "educates" microglia/macrophages to provide a supportive microenvironment, increased Ccr2, Cx3cr1, Tmem119, Nos2, Tnf, and Arg1 expression was also found in MACS-isolated Foxn1 ${ }^{-1-}$ brain microglia/macrophages following activated T-cell coculture (Supplemental Fig. S5A-F).

While T cells account for only 3\%-7\% of the immune cells in the naïve mouse brain (Korin et al. 2017), they could potentially interact with parenchymal cells, such as microglia. Alternatively, T-cell-microglia/macrophage interactions could take place outside of the brain. In this regard, reduced Cc15 levels were also observed in spleen monocytes isolated from athymic mice (Supplemental Fig. S5G), revealing a more pervasive defect in Foxn $1^{-1-}$ monocytes.

In multiple sclerosis, T-cell activation and direct T-cell-microglia/macrophage cell contact are both necessary to induce the production of soluble mediators (e.g., IFN $\gamma$, IL-10, iNOS, and TNFa), which in turn alter the local microenvironment (Carson et al. 1999; Chabot et al. 1999; Dasgupta et al. 2002). To determine whether $\mathrm{T}$-cell activation is required for $\mathrm{T}$ cells to increase microglial Ccl5 expression, athymic mouse brain microglia were grown in the presence of CM from activated or nonactivated (naïve) T cells. Increased Ccl5 RNA and protein expression was observed only in microglia cocultured with activated, but not nonactivated, $\mathrm{T}$ cells (Fig. 5E,F).

$T$ cells can prime microglia/macrophages by direct interactions (e.g., cell membrane ligand-receptor engagement) or indirect mechanisms (e.g., secrete soluble mediators). To ascertain whether direct cell-cell contact is required for $\mathrm{T}$ cells to increase microglia/macrophage Ccl5 expression, Foxn $1^{-/-}$brain microglia/macrophages were exposed to CM collected from activated T cells. Activated T-cell CM alone was sufficient to increase Ccl5 RNA and protein expression from athymic mouse microglia/macrophages to levels similar to that observed following the addition of T cells (Fig. 5G,H). While T-cell-microglia/macrophage interaction requires $\mathrm{T}$-cell activation, but not direct cellcell contact, future studies will be required to define the mechanisms underlying $\mathrm{T}$-cell activation in these pediatric LGGs and the soluble factors responsible for mediating microglia/macrophage priming.

Taken together, we demonstrated that activated $\mathrm{T}$ cells secrete soluble factors that stimulate microglia to express Ccl5, which provides a supportive microenvironment for o-GSC engraftment. These studies establish acquired LGG-promoting defects in Foxn1 $1^{-/-}$microglia/macrophages that result from a failure of T-cell "education." The inability of T cells to interact with microglia/macrophages in athymic mice may represent one barrier to successful PA patient-derived xenograft engraftment and the development of human preclinical LGG models. In addition, the instructive function of $\mathrm{T}$ cells in priming microglia/macrophages to create a permissive microenvironment for glioma formation and maintenance suggests additional therapeutic strategies that interrupt these important tumor ecosystem interactions.
Materials and methods

Mice

One-month-old male wild-type (B6-M) and athymic (Foxn1 ${ }^{-1-}$; B6NU-M) C57BL/6 mice were purchased from Taconic Biosciences. Cx3cr1 ${ }^{+/ G F P}$ and $\mathrm{Ccr}^{+/ \mathrm{RFP}}$ mice (Keiko Hirose, Washington University) were intercrossed to generate $\mathrm{Cx} 3 \mathrm{Cr}^{-1-} \mathrm{Ccr}^{-1-}$ and $\mathrm{Ccr}^{-/-}$mice. $\mathrm{Ccl}^{-/-}$mice were purchased from the Jackson Laboratory (005090). Nf1 flox/flox and $\mathrm{Nf1} 1^{\text {flox/mut }}$; GFAP-Cre mice were generated as described previously (Bajenaru et al. 2003). All mice were maintained on a C57BL/6 background and used in accordance with an approved Animal Studies Committee protocol.

Stem cell culture

o-GSCs and neural stem cells were isolated and cultured as described previously (Chen et al. 2015; Pan et al. 2017) and detailed in the Supplemental Material.

Isolation of microglia/macrophages

Microglia/macrophages were isolated and cultured using an established protocol with modifications (Moussaud and Draheim 2010) and as detailed in the Supplemental Material.

\section{T-cell culture}

Wild-type mouse spleens were homogenized in PBS containing $0.1 \%$ BSA and $0.6 \%$ Na-citrate, washed, and incubated with 120 Kunitz units of DNase I for $15 \mathrm{~min}$ at room temperature. Single-cell suspensions were obtained by filtering through a $30-\mu \mathrm{m}$ strainer followed by red blood cell lysis (eBioscience, 00433357) and negative selection using the pan-T-cell isolation kit II (Miltenyi Biotec, 130-095-130). T cells were grown in RPMI-1640 medium supplemented with $10 \% \mathrm{FBS}$ and $1 \% \mathrm{P} / \mathrm{S}$.

In situ phagocytosis assay

The phagocytosis assay was performed as described previously (Wendt et al. 2017) and detailed in the Supplemental Material.

IHC

Mice were euthanized and perfused in Ringer's solution and then in 4\% paraformaldehyde, and the brains and optic nerves/chiasms were dissected for IHC using primary and secondary antibodies as reported previously (Supplemental Table S1; Chen et al. 2015) and detailed in the Supplemental Material.

\section{Statistical analyses}

Data analyses were performed using Graphpad Prism. Unpaired two-tailed Student's $t$-tests were used to determine differences between two groups. All data are presented as mean values with standard deviation. All in vitro experiments have at least three repeats with similar results. The number of biological repeats is indicated as the number of dots in the scatter plots.

\section{Acknowledgments}

This work was supported by grants from the National Institutes of Health (1-R01-CA195692-01 and 1-R35-NS07211-01 to D.H.G.) and P30-CA91942 and UL1-TR000448 (Hope Center Viral Vectors Core and the Genome Technology Access Center). Y.P. was supported by a James S. McDonnell Foundation Fellowship. U.K. was supported by a Berlin Institute of Health-Einstein Fellowship grant (to D.H.G.).

Author contributions: Y.P., M.X., and D.H.G. conceived the study. Y.P., M.X., R.C., Y.M., C.C., S.D., Y.-H.C., M.M., M.S., and U.K. performed the investigation. Y.P. and D.H.G. wrote the manuscript. D.H.G. supervised the study. 


\section{References}

Albuquerque AS, Marques JG, Silva SL, Ligeiro D, Devlin BH, Dutrieux J, Cheynier R, Pignata C, Victorino RM, Markert ML, et al. 2012. Human FOXN1-deficiency is associated with $\alpha \beta$ double-negative and FoxP3 ${ }^{+}$ T-cell expansions that are distinctly modulated upon thymic transplantation. PLoS One 7: e37042.

Bajenaru ML, Hernandez MR, Perry A, Zhu Y, Parada LF, Garbow JR, Gutmann DH. 2003. Optic nerve glioma in mice requires astrocyte Nf1 gene inactivation and Nf1 brain heterozygosity. Cancer Res 63: 8573-8577.

Carson MJ, Sutcliffe JG, Campbell IL. 1999. Microglia stimulate naive T-cell differentiation without stimulating T-cell proliferation. I Neurosci Res 55: 127-134.

Chabot S, Williams G, Hamilton M, Sutherland G, Yong VW. 1999. Mechanisms of IL-10 production in human microglia-T cell interaction. Immunol 162: 6819-6828.

Chabot S, Yong FP, Le DM, Metz LM, Myles T, Yong VW. 2002. Cytokine production in T lymphocyte-microglia interaction is attenuated by glatiramer acetate: a mechanism for therapeutic efficacy in multiple sclerosis. Mult Scler 8: 299-306.

Chang AL, Miska J, Wainwright DA, Dey M, Rivetta CV, Yu D, Kanojia D, Pituch KC, Qiao J, Pytel P, et al. 2016. CCL2 produced by the glioma microenvironment is essential for the recruitment of regulatory $\mathrm{T}$ cells and myeloid-derived suppressor cells. Cancer Res 76: 5671-5682.

Chen YH, McGowan LD, Cimino PJ, Dahiya S, Leonard JR, Lee DY, Gutmann DH. 2015. Mouse low-grade gliomas contain cancer stem cells with unique molecular and functional properties. Cell Rep 10: 1899-1912.

Chen Z, Feng X, Herting CJ, Garcia VA, Nie K, Pong WW, Rasmussen R, Dwivedi B, Seby S, Wolf SA, et al. 2017. Cellular and molecular identity of tumor-associated macrophages in glioblastoma. Cancer Res 77: 2266-2278.

Daginakatte GC, Gutmann DH. 2007. Neurofibromatosis-1 (Nf1) heterozygous brain microglia elaborate paracrine factors that promote Nf1deficient astrocyte and glioma growth. Hum Mol Genet 16: 1098-1112.

Daginakatte GC, Gianino SM, Zhao NW, Parsadanian AS, Gutmann DH. 2008. Increased c-Jun-NH2-kinase signaling in neurofibromatosis-1 heterozygous microglia drives microglia activation and promotes optic glioma proliferation. Cancer Res 68: 10358-10366.

Dasgupta S, Jana M, Liu X, Pahan K. 2002. Myelin basic protein-primed T cells induce nitric oxide synthase in microglial cells. Implications for multiple sclerosis. J Biol Chem 277: 39327-39333.

Feng X, Szulzewsky F, Yerevanian A, Chen Z, Heinzmann D, Rasmussen RD, Alvarez-Garcia V, Kim Y, Wang B, Tamagno I, et al. 2015. Loss of CX3CR1 increases accumulation of inflammatory monocytes and promotes gliomagenesis. Oncotarget 6: 15077-15094.

Griesinger AM, Birks DK, Donson AM, Amani V, Hoffman LM, Waziri A, Wang M, Handler MH, Foreman NK. 2013. Characterization of distinct immunophenotypes across pediatric brain tumor types. J Immunol 191: 4880-4888.

Hoyt WF, Baghdassarian SA. 1969. Optic glioma of childhood. Natural history and rationale for conservative management. Br I Ophthalmol 53: 793-798.

Htain WW, Leong SK, Ling EA. 1994. A comparative Mac-1 immunocytochemical and lectin histochemical study of microglial cells in the normal and athymic mice. Glia 12: 44-51.

Keren-Shaul H, Spinrad A, Weiner A, Matcovitch-Natan O, Dvir-Szternfeld R, Ulland TK, David E, Baruch K, Lara-Astaiso D, Toth B, et al. 2017. A unique microglia type associated with restricting development of Alzheimer's disease. Cell 169: 1276-1290.e17.

Korin B, Ben-Shaanan TL, Schiller M, Dubovik T, Azulay-Debby H, Boshnak NT, Koren T, Rolls A. 2017. High-dimensional, single-cell charac- terization of the brain's immune compartment. Nat Neurosci 20: 1300-1309.

Krasemann S, Madore C, Cialic R, Baufeld C, Calcagno N, El Fatimy R, Beckers L, O'Loughlin E, Xu Y, Fanek Z, et al. 2017. The TREM2APOE pathway drives the transcriptional phenotype of dysfunctional microglia in neurodegenerative diseases. Immunity 47: 566-581.e9.

Mahdi J, Shah AC, Sato A, Morris SM, McKinstry RC, Listernick R, Packer RJ, Fisher MJ, Gutmann DH. 2017. A multi-institutional study of brainstem gliomas in children with neurofibromatosis type 1. Neurology 88: 1584-1589.

Mizutani M, Pino PA, Saederup N, Charo IF, Ransohoff RM, Cardona AE. 2012. The fractalkine receptor but not CCR2 is present on microglia from embryonic development throughout adulthood. I Immunol 188: 29-36.

Morton CL, Houghton PJ. 2007. Establishment of human tumor xenografts in immunodeficient mice. Nat Protoc 2: 247-250.

Moussaud S, Draheim HJ. 2010. A new method to isolate microglia from adult mice and culture them for an extended period of time. I Neurosci Methods 187: 243-253.

Nehls M, Pfeifer D, Schorpp M, Hedrich H, Boehm T. 1994. New member of the winged-helix protein family disrupted in mouse and rat nude mutations. Nature 372: 103-107.

Oh J, Wang W, Thomas R, Su DM. 2017. Capacity of tTreg generation is not impaired in the atrophied thymus. PLOS Biol 15: e2003352.

Pan Y, Bush EC, Toonen JA, Ma Y, Solga AC, Sims PA, Gutmann DH. 2017. Whole tumor RNA-sequencing and deconvolution reveal a clinically-prognostic PTEN/PI3K-regulated glioma transcriptional signature. Oncotarget 8: 52474-52487.

Pong WW, Higer SB, Gianino SM, Emnett RJ, Gutmann DH. 2013. Reduced microglial CX3CR1 expression delays neurofibromatosis-1 glioma formation. Ann Neurol 73: 303-308.

Raabe EH, Lim KS, Kim JM, Meeker A, Mao XG, Nikkhah G, Maciaczyk J, Kahlert U, Jain D, Bar E, et al. 2011. BRAF activation induces transformation and then senescence in human neural stem cells: a pilocytic astrocytoma model. Clin Cancer Res 17: 3590-3599.

Simmons GW, Pong WW, Emnett RJ, White CR, Gianino SM, Rodriguez FJ, Gutmann DH. 2011. Neurofibromatosis-1 heterozygosity increases microglia in a spatially and temporally restricted pattern relevant to mouse optic glioma formation and growth. I Neuropathol Exp Neurol 70: $51-62$.

Solga AC, Pong WW, Kim KY, Cimino PJ, Toonen JA, Walker J, Wylie T, Magrini V, Griffith M, Griffith OL, et al. 2015. RNA sequencing of tumor-associated microglia reveals $\mathrm{Ccl} 5$ as a stromal chemokine critical for Neurofibromatosis-1 glioma growth. Neoplasia 17: 776-788.

Venkatesh HS, Tam LT, Woo PJ, Lennon J, Nagaraja S, Gillespie SM, Ni J, Duveau DY, Morris PJ, Zhao JJ, et al. 2017. Targeting neuronal activityregulated neuroligin-3 dependency in high-grade glioma. Nature 549: 533-537.

Wendt S, Maricos M, Vana N, Meyer N, Guneykaya D, Semtner M, Kettenmann H. 2017. Changes in phagocytosis and potassium channel activity in microglia of $5 \mathrm{xFAD}$ mice indicate alterations in purinergic signaling in a mouse model of Alzheimer's disease. Neurobiol Aging 58: 41-53.

Yang I, Han SJ, Sughrue ME, Tihan T, Parsa AT. 2011. Immune cell infiltrate differences in pilocytic astrocytoma and glioblastoma: evidence of distinct immunological microenvironments that reflect tumor biology. J Neurosurg 115: 505-511.

Zhu Y, Harada T, Liu L, Lush ME, Guignard F, Harada C, Burns DK, Bajenaru ML, Gutmann DH, Parada LF. 2005. Inactivation of NF1 in CNS causes increased glial progenitor proliferation and optic glioma formation. Development 132: 5577-5588. 


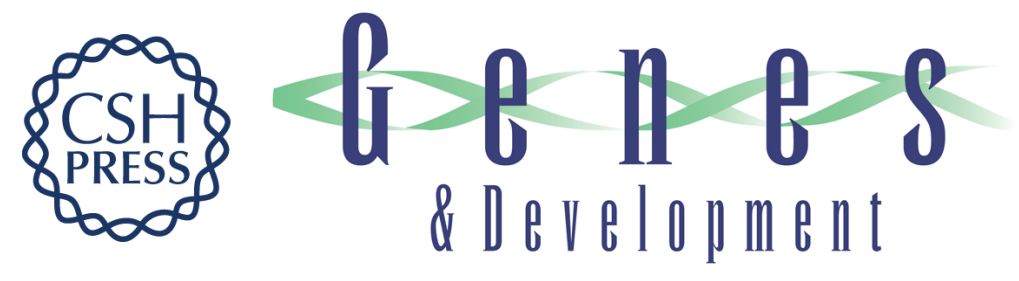

\section{Athymic mice reveal a requirement for T-cell-microglia interactions in establishing a microenvironment supportive of $\mathbf{N f 1}$ low-grade glioma growth}

Yuan Pan, Min Xiong, Ran Chen, et al.

Genes Dev. 2018, 32: originally published online April 9, 2018

Access the most recent version at doi:10.1101/gad.310797.117

Supplemental Material

References

Creative

Commons

License

Email Alerting

Service
http://genesdev.cshlp.org/content/suppl/2018/04/09/gad.310797.117.DC1

This article cites 33 articles, 11 of which can be accessed free at: http://genesdev.cshlp.org/content/32/7-8/491.full.html\#ref-list-1

This article is distributed exclusively by Cold Spring Harbor Laboratory Press for the first six months after the full-issue publication date (see http://genesdev.cshlp.org/site/misc/terms.xhtml). After six months, it is available under a Creative Commons License (Attribution-NonCommercial 4.0 International), as described at http://creativecommons.org/licenses/by-nc/4.0/.

Receive free email alerts when new articles cite this article - sign up in the box at the top right corner of the article or click here.

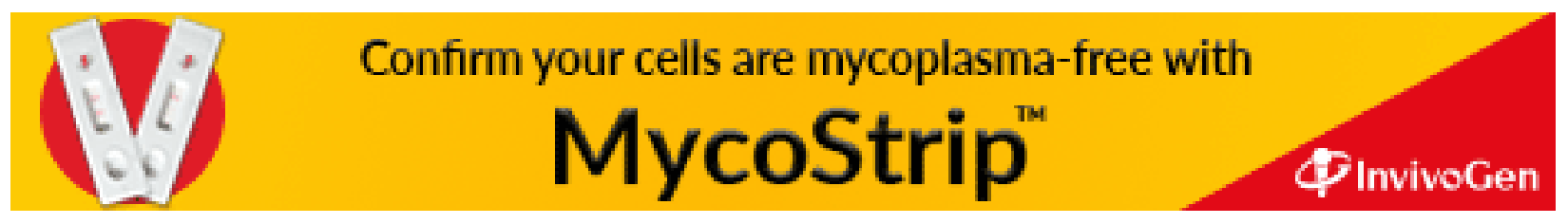

